УДК $782.082+786.2$

ORCID: 0000-0002-6112-4862

Чжсо Дапин, преподаватель Лэшаньского педагогического университета, соискатель кафедры теории музыки и композиции ОНМА имени А. В. Неждановой ул. Новосельского, 63, Одесса, 65023, Украина

Zhou Daping, Lecturer at the Leshan Normal University, Applicant at the Department of Music Theory and Composition, Odessa National A. V. Nezhdanova Academy of Music 63 Novoselskogo St., Odessa 65023, Ukraine

\title{
ЖАНРОВАЯ ОБРАЗНОСТЬ В ПОЭТИКЕ ФОРТЕПИАННОГО ИСКУССТВА ХХ ВЕКА
}

Опираясь на философские, психологические и музыковедческие представления об образном содержании, жанре и стиле музыки, на метод жанрово-стилевого анализа музыкального текста, автор выводит определение понятия «жанровой образности», выявляет стилевое основание данного вида художественно-образного смысла музыки, отмечает особенности отношения композиторов XX века к жанровой основе музыкального творчества, подчеркивает значение стилизации в поэтике современной музыки и анализирует проявления жанровой образности в цикле Д. Лигети «Musica ricercata». Полученные выводы позволяют планировать разработку методов освоения современных произведений в процессе обучения пианистов.

Ключевые слова: художественный образ, жанр, стиль, стилизация, фортепианная музыка, XX век, обучение игре на фортепиано.

Чж⿻у Дапін. Жанрова образність у поетиці фортепіанного мистецтва XX століття. Спираючись на філософські, психологічні та музикознавчі уявлення про образний зміст, жанр і стиль музики, на метод жанрово-стильового аналізу музичного тексту, автор виводить дефініцію поняття «жанрової образності», виявляе стильові засади даного виду художньо-образного змісту музики, відзначає особливості ставлення композиторів XX століття до жанрової основи музичної творчості, підкреслює значення стилізації в поетиці сучасної музики та аналізує прояви жанрової образності в циклі Д. Лігеті «Musica ricercata». Отримані висновки дозволяють планувати розробку методів освоєння сучасних творів у процесі навчання піаністів. 
Ключові слова: художній образ, жанр, стиль, стилізація, фортепіанна музика, XX століття, навчання грі на фортепіано.

Zhou Daping. Genre imagery in the poetics of the twentieth century piano art. Basing on the philosophical, psychological and musicological ideas about the imaginative content, genre and style of music, the author deduces the definition of the «genre imagery» concept, reveals the stylistic basis of this type of artistic sense of music, notes the peculiarities of the 20th century composers' attitude to the genre-based musical creativity, emphasizes the importance of stylization in the poetics of modern music and analyzes the manifestations of genre imagery in D. Ligeti's cycle «Musica ricercata». The obtained results make it possible to plan the development of methods for modern works mastering in the process of pianists training.

Key words: image, genre, style, stylization, piano music, the twentieth century, playing the piano.

Постановка проблемы. Необходимость исследования теоретического вопроса, сформулированного в заглавии статьи, вызвана практической проблемой музыкально-исполнительского искусства и музыкальной педагогики. Речь идет о проблеме понимания и творческого освоения музыки прошлого столетия (условно говоря, современной музыки) основной массой будущих музыкантов-исполнителей учащимися средних и высших музыкально-образовательных учреждений. Эта проблема особенно актуальна для Китая и других стран Азии, где сегодня интенсивно осваиваются традиции европейской музыкальной культуры. Одним из самых динамичных направлений этого процесса является освоение фортепианного исполнительского искусства. Сегодня фортепиано стало чрезвычайно популярным инструментом массового музицирования. Несколько десятков миллионов детей, подростков и представителей юношества обучается сегодня игре на фортепиано. Китайские музыканты-профессионалы все чаще и все лучше проявляют себя на международных конкурсах, участвуют в фестивалях, важных культурных проектах. Резко вырос и уровень знакомства массы населения с лучшими образцами классического фортепианного искусства.

Вместе с тем, мы должны отметить досадный факт: концертирующие музыканты-исполнители Китая, студенты консерваторий, музыкальных колледжей и школ, а вслед за ними и широкая масса слушателей уделяют сравнительно мало внимания современной музыке. Это относится и к тем произведениям европейских композиторов (Б. Бартока, А. Веберна, В. Лютославского, О. Мессиана, Д. Мийо, Ф. Пуленка, С. Прокофьева, 
И. Стравинского, П. Хиндемита, А. Шенберга и др.), которые уже давно стали классикой в широком смысле этого слова. Редко это признается открыто, но судя по фактическому состоянию музыкально-исполнительской и академической практики, многие музыканты плохо понимают современную фортепианную музыку и не испытывают к ней приязненных чувств.

В современной китайской музыке такое отношение проявляется не столь явно. Во-первых, вся китайская фортепианная музыка относится к XX веку. Во-вторых, ее исполнение правомерно рассматривается как художественная пропаганда родной культуры, которая поддерживается государством, а также как проявление патриотизма. В-третьих, произведения китайских композиторов более понятны и близки отечественным исполнителям, поскольку они, как правило, опираются на музыкальный язык и поэтику многонациональной традиционной культуры Китая. Несмотря на отмеченный приоритет китайских произведений для фортепиано в учебном и концертном репертуаре китайских музыкантов-исполнителей, качество их художественной интерпретации все-таки оставляет желать лучшего.

Полагаем, что одна из причин охарактеризованной ситуации в музыкально-исполнительской практике в КНР - недостаточно ясное, поверхностное, безразличное и неподготовленное понимание китайскими пианистами художественно-образного содержания произведений современной музыки. Можно ли исправить этот недостаток и улучшить подготовку китайских пианистов к исполнению современной музыки? Полагаем, что это решаемая задача. Один из путей ее решения состоит в формировании у музыкантов-исполнителей умения выявлять и творчески воплощать художественно-образный смысл, обусловленный жанровостилевыми свойствами исполняемых произведений.

Таким образом, теоретическая актуальность поставленной проблемы заключается в необходимости специального изучения жанровой образности как феномена музыкальной поэтики и выявления специфики этого феномена в фортепианных произведениях композиторов XX века. Практическая актуальность состоит в возможности применения знаний о жанровой образности современной музыки в процессе подготовки профессиональных музыкантов-исполнителей.

Цель статьи - прояснить сущность феномена жанровой образности в поэтике фортепианного искусства XX века. Задачи статьи: а) определить содержание термина жанровая образность; б) охарактеризовать в общих чертах средства воплощения данного типа образного содержания в произведениях европейской классической музыки; в) выявить основные тенденции воплощения жанровой образности в фортепианной музыке XX века. 
Методы исследования: компаративный анализ и понятийное моделирование, использованные в решении задачи определения ключевых понятий жанра, стиля, жанровой образности; жанрово-стилевой анализ музыкального текста фортепианных произведений Д. Лигети.

Степень изученности проблемы. Жанровые свойства фортепианной музыки и связанные с ними вопросы интерпретации исследованы достаточно широко и основательно. Так, скажем, история жанров клавирной музыки представлена в работах А. Алексеева [1]. Генезис и многообразные взаимоотношения жанров фортепианной музыки представлены в монографии В. Клина [5]. Жанровые особенности произведений композиторов XX века отражены в трудах Д. Буржа [19], Л. Гаккеля [3], К. Гартнер [23], Ф. Кирби [22], Пин-Тин Лана [20], А. Шокли [21] и других исследователей фортепианного искусства. Укажем также на значительное количество работ китайских авторов, где чаще всего поверхностно затронуты жанровые свойства мировой и отечественной фортепианной музыки (Бу Ли, Бянь Мэн, Ван Аньго, Ван Юйхэ, Вэй Тингэ, Гао Сяогуан, Гуанъ Цзяньхуа, Дай Понхай и др.).

К сожалению, в обширном массиве работ, посвященных жанровым сторонам и свойствам фортепианной музыки, ученые редко выделяют и специально исследуют вопрос о том, как именно в произведениях современной фортепианной музыки запечатлеваются и семантически функционируют жанры музыки народной, ритуальной, классической, популярно-массовой. Именно эта сторона проблемы остается пока мало исследованной. Мы полагаем, что данную проблему целесообразно исследовать в проекции трех важнейших категорий теоретического музыкознания: жанра, стиля и поэтики. В нашей работе мы опираемся на труды, посвященные всеобщей теории музыкальных жанров и стилей (М. Михайлова, И. Коханик, М. Лобановой, В. Медушевского, В. Москаленко, Е. Назайкинского, А. Сохора, С. Тышко, С. Шипа); а также на положения психологии, раскрывающие суть феноменов образа и смысла.

Результаты исследования. Одним из опорных понятий исследования является понятие образа. Образ - чрезвычайно емкое по своему значению слово. Оно служит одной из центральных категорий философии, психологии, эстетики и искусствоведения. Трактовки данного понятия могут быть очень разными. Они зависят от системы взглядов того или иного ученого, от всего понятийного аппарата той или иной научной концепции. Например, в материалистической философии «образ» трактуется как «результат отражения объекта в сознании человека. На чувственной ступени познания образами являются ощущения, восприятия 
и представления, на уровне мышления - понятия, суждения и умозаключения. Образ объективен по своему источнику - отражаемому объекту и субъективен по способу (форме) своего существования. Материальной формой воплощения образа выступают практические действия, язык, различные знаковые модели. Специфической формой образа является художественный образ» [16, с. 447]. Такое определение может быть оспорено с иных онтологических позиций. Однако большинство философов сходятся в прагматической оценке данного явления, когда утверждают, что образ «играет активно-действенную роль в поведении человека и животных. Он регулирует поведение, осуществляет функции управления действиями» [там же].

Приведенное определение сопоставимо с представлениями психологов структурно-позитивистского направления. По формулировке К. Платонова, образ - это «субъективное психическое явление», выступающее результатом познавательных процессов. «Различают образы: элементарные (ощущений), свойственные и животным, и сложные идеальные (восприятий и понятий), свойственные только человеку; непосредственные (по анализаторам), опосредованные (описанием, чтением не только текста, но и приборов) и следовые (памяти), статичные и динамичные; самостоятельные и включенные в другие психические явления (мышление, волевые действия)» [11, с. 77-78].

Яркость, отчетливость, субъективность, нетождественность объектам отражения, оригинальность, не выходящая за рамки психологической нормы, присущи художественному мышлению. Эти свойства, отмеченные еще в античной эстетике, систематически осмысленные Г. Ф. В. Гегелем и другими философами романтической эпохи, позволили В. Белинскому определить искусство как «непосредственное созерцание истины или мышление в образах». «Образ, - пишет И. Роднянская, - всеобщая категория художественного творчества; присущая искусству форма воспроизведения, истолкования и освоения жизни путем создания эстетически воздействующих объектов. Под образом нередко понимается элемент или часть художественного целого, обыкновенно - такой фрагмент, который обладает как бы самостоятельной жизнью и содержанием... Но в более общем смысле образ - самый способ существования произведения, взятого со стороны его выразительности, впечатляющей энергии и значимости» [13].

Приведенные дефиниции понятия «образ» дают достаточно ясные основания для определения производной от него лексической единицы «образность». Последний термин получил распространение главным 
образом в искусствознании и филологии. Так, например, лингвисты и филологи понимают образность в узком смысле слова как стилевой признак художественной речи, который заключается в употреблении слов в их переносном значении - метафор, эпитетов, сравнений, гипербол и др. [12]. То есть, художественная речь, в отличие от речи обыкновенной, бытовой, отличается именно образностью. Заметим, что этот основной смысл термина варьируется и дополняется, попадая в контекст разных лингвистических и литературоведческих концепций. По замечанию Д. Ольховикова, «производное слово-термин “образность” находится в сложных отношениях синонимии с рядом близких по значению семантикостилистических категорий: “выразительность”, “экспрессивность”, “метафоричность" (в широком смысле слова), в работах некоторых авторов - “символичность" и “поэтичность" (к примеру, у А. Потебни)» [10, c. 341]. Показательно, что и в научной, и в художественной литературе слово образность соотносится с богатым рядом синонимов, среди которых самым частотным является слово выразительность, а также художественность, выпуклость, живость, метафоричность, красочность, красноречивость, рельефность, иносказательность, живописность, картинность, экспрессия, фигуральность.

Музыковедение не может в полной мере воспользоваться лингвистическим подходом к трактовке понятия «образность» по той причине, что безо́бразная (или, как говорят еще, «нонтропическая») речь со всей очевидностью существует в любой культуре, но безо́бразной музыки, то есть такой музыки, которая не имеет признаков образного содержания, не может быть по определению (музыка, в любом понимании этого слова, - это вид искусства, феномен художественной деятельности человека).

Поэтому под музыкальной образностью в широком смысле этого выражения условимся понимать весь план художественного содержания музыки (перцептивные образы, эмоциональные переживания, психические модальности, наглядные представления и понятия, в том числе - значения и личностные смыслы, порождаемые восприятием музыкально-интонационной формы). В узком смысле слова (близком к филологической интерпретации), образность - это наглядно-чувственное, картинное, персонифицированное содержание определенных интонационных свойств или элементов формы.

Теперь рассмотрим понятие жсанра. По определению С. Шипа (оно в основных пунктах согласуется с суждениями Е. Назайкинского [9, с. 9495]), термин «жанр» имеет два значения: «1) Тип музицирования или музыкального произведения, который естественно возникает, развивается, исчезает или трансформируется в культурной среде в соответствии с 
потребностями общества. Характеризуется определенным комплексом функций, условий существования, образно-содержательных и формальных свойств. 2) Типологическое представление о музыкальных артефактах, которое активно участвует в создании, исполнении и слушании музыки, и обычно отражается в музыкально-теоретических понятиях» [17]. Оба значения существенны для понимания интересующей нас проблемы.

Естественный процесс образования музыкальных жанров опирается на три основания: 1) функциональное родство конкретных артефактов и актов музыкального творчества; 2) кондициональное родство, обеспеченное комплексом необходимых условий, обстоятельств, при которых произведения реализуют свои культурные функции; 3) семантическое (образно-содержательное) родство. Последнее проявляет себя в подобии героев, сюжетов, психологических модальностей, чувственных представлений, идей, присущих функционально и кондиционально родственным явлениям музыкального творчества.

Важным понятием теории музыкального жанра является понятие жанрового стиля. По принятому в музыковедческой литературе убеждению, данное понятие разработано А. Сохором. При этом ошибочно указывают на статью «Стиль, метод, направление (к определению понятий)» [2], хотя в ней нет рассуждений о жанрах. Выражение «жанровый стиль», подготовленное трудами М. Бахтина, Г. Бесселера, К. Дальхауза, Б. Яворского и других ученых предельно ясно представлено в работе А. Сохора «Эстетическая природа жанра в музыке», где говорится о том, что «есть некоторые устойчивые закономерные черты у всех исторически меняющихся форм быта, театральных спектаклей, концертов, культовых обрядов. Они-то и проявляются в специфике содержания соответствующих музыкальных жанров и в качественном своеобразии их формы, то есть в их с т и ле» [15, с. 250, разрядка наша. - Ч. Д.].

Принимая понятие жанрового стиля, мы не можем присоединиться к категоричному разделению А. Сохором стиля и содержания, которое следует из его понимания стиля как сугубо формальной характеристики произведений искусства. В интерпретации категории стиля мы придерживаемся иной точки зрения, согласно которой данное понятие охватывает не только формальные, но и образно-содержательные свойства художественных артефактов: «Стиль - устойчивое единство образной системы, выразительных средств, характеризующее художественное своеобразие тех или иных совокупностей явлений искусства, будь то крупная художественная эпоха, отдельное художественное направление или манера отдельного художника» [12]. 
Подчеркнем важное для нашего исследования понятие образа (образной системы), включенное в вышеприведенную формулировку стиля. Стиль, присущий тому или иному жанру (то есть, жанровый стиль), не исчерпывает всех смыслов, связанных с родовой категорией музыки. Вместе с тем, каждый жанровый стиль, обусловленный названными выше функциональными и кондициональными факторами, репрезентирует типичную художественную образность данного жанра, так сказать, его художественно-выразительное лицо. Жанровый стиль «охватывает все уровни и компоненты формы: звук, материал, музыкальный язык (принципы организации звуковой высоты, ритма, темпа, артикуляции и динамики, интонационный тезаурус, принципы синтаксического упорядочения музыкального текста), фактуру и тематическую структуру (композицию)» [17]. С другой стороны, жанровый стиль являет собой индивидуально-типологические свойства художественной образности: чувственные представления, психические модальности, идеи, образы персонажей, в которых проявляется образ «поведения человека, способ видения, слышания и мышления» (И. Иоффе [4]), «единство музыкального мышления» (М. Михайлов [8]), «психологический образ мира» (А. Леонтьев [6]). Думается, мы можем с уверенностью высказать следующий тезис: жанровый стиль - это главный носитель художественной образности того или иного музыкального жанра.

Теперь рассмотрим понятия образности и жанрового стиля в проекции на конкретное музыкальное произведение. Обратим внимание читателя на тот факт, что любое музыкальное произведение может получить двойственную, а то и тройственную жанровую характеристику.

Прежде всего, произведение имеет, как правило, некое жанровое наименование («жанроним», по выражению С. Шипа). Его автором обычно выступает композитор, реже - редактор нотного издания, еще реже- общественное мнение. Функции жанронимов очевидны. Вопервых, они дают исполнителям и слушателям самое общее представление о форме и содержании произведения, которое им предстоит исполнять и воспринимать. Письменное или устное указание на некий конкретный жанр создает психологическую настройку (в более точном смысле - установку восприятия), что способствует пониманию образного содержания произведения. Во-вторых, жанровые названия произведений помогают профессионалам и любителям искусства ориентироваться в обширном поле музыкальных артефактов. Менее всего жанронимы способны служить терминами, пригодными для научного изучения и описания родов, видов и разновидностей музыкального 
творчества. Лишь небольшая их часть удовлетворяет требованиям, предъявляемым к научному терминологическому аппарату.

Второй аспект оценки жанра единичного музыкального произведения - это оценка его функциональных, кондициональных и семантических свойств. Наибольшее значение имеют коммуникативная, экспрессивная, гедонистическая, ценностная, познавательная, социальноорганизующая, психотропная, терапевтическая, ритуально-магическая, воспитательная функции. К числу наиболее важных кондициональных свойств жанра относятся свойства инструментов и/или поющих голосов, количество и качество исполнителей, акустические условия среды, количество и качество слушателей, временной регламент звучания. К важнейшим художественно-семантическим жанровым свойствам произведения относятся эмоциональные модальности, типы движения, коррелирующие с интонационным процессом, чувственные представления, идеи, эстетические модальности (эпическая, драматическая, лирическая, трагическая, комическая и т. д.).

Заметим, что жанроним может вступить в противоречие с фактическими жанровыми свойствами конкретного произведения. Такое противоречие обычно свидетельствует о недостаточной образованности автора. К примеру, самодеятельные композиторы или маленькие дети, увлекающиеся музыкальным творчеством, могут назвать сонатой миниатюрную пьеску. Впрочем, иногда несоответствие названия произведения и его действительного жанра имеет иные субъективные причины. А. Сохор отмечает в связи с некоторыми конкретными просчетами композиторов (Р. Шумана, Ж. Массне, К. Сен-Санса): «мы видим, что жанровая принадлежность произведения определяется не субъективными факторами (обозначение, данное композитором и указывающее на обстановку исполнения, на которую оно рассчитано; желания и намерения исполнителей, обратившихся к нему, и т. п.), а объективными: соответствие его содержания и стиля требованиям тех или иных условий бытования музыки. И если композитор ошибочно (или слишком узко) определил жанр своего сочинения, общественная практика поправляет его» [15, с. 274].

Более интересны случаи, когда автор произведения допускает несоответствие жанронима и фактического жанра намеренно. В таком случае возникает своеобразная художественная «игра с восприятием» публики, вызывающая эффекты удивления, недоумения, комического или трагического конфликта. Подобный прием рассогласования свойств фактического жанра и смысла названия присущ композиторам постмодернистской ориентации. 
Третий аспект анализа и оценки жанра музыкального произведения это выявление в форме и образном содержании произведения свойств некоторого имплицитного, необъявленного, не обозначенного названием жанрового стиля. Особенно интересны случаи, когда форма, имеющая явные признаки одного жанра, обнаруживает стилевые свойства другого жанра. Такая ситуация возможна, поскольку возможным является последовательное или даже одновременное соединение в одном музыкальном тексте свойств разных жанровых стилей. Подчеркнем, что мы не имеем в виду синтетические (то есть, слившиеся, устойчиво соединившиеся) жанровые стили, подобные, например, стилям песенных маршей или танцевальных песен. Речь идет о достаточно многочисленных случаях, когда какой-то жанровый стиль воспроизводится именно как иной, вошедший в художественный текст «со стороны».

Так, например, в сонатах, квартетах, симфониях Бетховена нередко применяется выразительный прием жанровой стилизации (в общем виде он охарактеризован в работе С. Шипа [18]). Суть данного приема состоит в следующем: в музыкальной форме, выдержанной в жанровом стиле виртуозно-моторной или танцевальной инструментальной пьесы, неожиданно появляются признаки вокально-декламационного стиля, присущего жанрам оперы и оратории. Возникает, во-первых, очень яркий эффект неожиданности от «столкновения» далеких жанровых стилей. Вовторых - и это подчеркнем особо - воспроизведенные интонационные и композиционные свойства речитативного стиля вносят вместе с собой и образные смыслы, присущие жанру речитатива. В воображении слушателей, вероятно, возникает картина театра или большого зала, образ оратора или сценического героя, появляются литературные, архитектурные, живописные и прочие ассоциации, актуализируются личностные смыслы, связанные с опытом восприятия и осмысления широкого круга жизненных явлений.

Таким образом, выразительный прием жанровой стилизации позволяет композиторам создавать богатейшие возможности для создания сложных музыкальных концепций, где жанровая образность играет ведущую роль. Роль и значение этого приема трудно переоценить. Особенно - для произведений так называемых «вторичных жанров».

Жанровая стилизация наглядно обнаруживает свойство музыкального жанра, подобно механизму памяти, хранить информацию о тех жизненных ситуациях, в которых жанр рождается, живет, развивается. Е. Назайкинский предложил называть данный феномен «памятью жанра»: «жанровая ситуация со всеми ее атрибутами, с одной стороны, входит весомой частью в хранимое памятью жанра содержание, с другой же - 
сама выступает как один из блоков памяти жанра, создает режим наибольшего благоприятствования для сохранения простых и естественных черт музыкального жанра» [9, с. 105]. Мнемонические способности жанра ярко обнаруживаются в приеме жанровой стилизации. Как пишет Е. Назайкинский, «музыкальный материал жанра в сознании слушателей, исполнителей, участников коммуникации вступает в прочную ассоциативную связь с жанровой ситуацией. И тогда, уже в других обстоятельствах и условиях, даже в другом историческом контексте, он начинает выполнять функцию напоминания о той прежней ситуации и вызывать определенные, окрашенные воспоминаниями эстетические переживания» [там же, с. 107].

Как нетрудно заметить, в творчестве композиторов XX века обнаружилась заметная тенденция к эксперименту не только в области музыкального языка и стиля, но также и в сфере музыкальных жанров. С одной стороны, культурная практика рождала новые первичные жанры и жанровые области (киномузыка, видеоклип, электронная музыка, хэппенинг, перформанс, психоделическая музыка и т. д.). Еще большее разнообразие наблюдается в сфере вторичных жанров. Здесь отмечается усиление интенции, возникшей еще у композиторов-романтиков, к созданию новых оригинальных жанров. Примеры такого рода жанровых инноваций в фортепианной музыке многочисленны: «Эстампы» К. Дебюсси, «Отражения» М. Равеля, «Гноссиенны» Э. Сати; «Сарказмы», «Наваждения» и «Мимолетности» С. Прокофьева и др. Заметим, что жанронимы упомянутых произведений имеют достаточно определенный и яркий образный смысл, отвечающий художественно-образному содержанию этих замечательных циклов. Поэтому их можно трактовать и как жанровые имена, и как программные заголовки. Композиторы-модернисты «второй волны» продолжили жанровые эксперименты в том же направлении. Они еще решительнее отошли от жанровой системы первичных и вторичных жанров. Их произведения нередко стали называться «сухо», абстрактно, например: «Пьеса для фортепиано» (Klavierstücke), «Композиция», «Музыка». К такому названию может прибавляться номер.

Одна из трудностей восприятия и исполнения подобных опусов заключается в том, что участникам музыкальной коммуникации трудно опереться на их личный или коллективный интонационно-речевой опыт. Разумеется, восприятие индивида даже в таких случаях находит некие опоры в сфере чувственных впечатлений и эмоций, в работе фантазии. Однако мышление реципиента не находит надежного основания для построения богатых, сложных и многообразно связанных образов. 
Сознание слушателя затрудняется связать воспринимаемые звуковые впечатления с личным опытом эстетического освоения действительности.

Впрочем, если в музыкальном произведении появляются хотя бы некоторые признаки известного слушателю жанрового стиля, звуковые формы тут же получают субъективное «оправдание», образную яркость, конкретность, значительность.

Примером виртуозного использования приема жанровой стилизации и может послужить фортепианный цикл Дьёрдя Лигети «Musica ricercata» (1951-1953). Этот цикл состоит из 11 миниатюрных пьес, каждая из которых демонстрирует в «обнаженном виде» определенный способ композиции, а также творческую фантазию и инженерное мастерство композитора. Этому замыслу цикла отвечает многозначное название, которое можно перевести с итальянского как «разысканная» или «найденная», или «открытая музыка». Данное название отчасти можно считать жанровым неологизмом. По меньшей мере, оно корреспондирует с ричеркаром - жанром профессиональной европейской музыки периодов позднего Возрождения и Барокко.

Несмотря на то, что по своему духу цикл Лигети представляет собой своеобразный «гимн конструктивизму», музыка этого сочинения отличается удивительной выразительностью, живостью, образным богатством. В этом отношении композитор следует по пути своего великого старшего соотечественника - Б. Бартока. Размышляя о семантических свойствах собственной музыки, Лигети отмечает, что ему чужд традиционный романтический принцип программности. Свой творческий метод он охарактеризовал так: «программная музыка без программ, музыка сильно насыщенная ассоциациями, но чистая музыка. Всё прямое и однозначное мне чуждо. Я люблю намеки, двусмысленности, многозначности, вещи с двойным дном. Многозначны также различные картинные ассоциации, связанные с моей музыкой, о которых я говорю и думаю, или которые я ощущаю, когда представляю себе мою музыку» [7, с. 151].

Мы полагаем, что к «намекам», упомянутым в высказывании Лигети, можно отнести жанрово-стилевые аллюзии (латинское allusio буквально означает «намёк»), присутствующие почти в каждой пьесе цикла. Так, например, первая пьеса, полностью (за исключением последнего звука) сконструированная на материале тона «ля», тонко стилизует жанр романтического скерцо, с присущими его стилю свойствами метра и ритма, фактуры, синтаксиса, резкими сменами артикуляции, ускорением движения и постепенным нагнетанием громкости. 
Вторая пьеса также отличается исключительным аскетизмом строительного материала, ограниченного тонами ми-диез, фра-диез и соль. Интонационной единицей служат секундовый восходящий и нисходящий ходы; ритм - однообразный, формульного типа, с «тормозящими» остановками на протяженных последних тонах. Господствует монодийный принцип фактурной организации и вариантно-строфический принцип композиционного построения пьесы. При всем нарочитом схематизме эти интонационные средства ассоциируются с жанровой областью псалмодической духовной музыки. Эту иллюзию усиливают два тонких приема: а) гетерофонное проведение основной тематической попевки одновременно в крайнем нижнем и крайнем верхнем регистрах фортепиано, вследствие чего создается акустическая иллюзия большого пространства, в котором звуки гулко «разносятся», как бы реверберируют. Во второй части композиции в верхнем звонком регистре фортепиано появляется предельно учащенная репетиция тона соль, вызывающая ассоциацию с тихим звоном алтарного колокольчика в католической службе. Таким образом, несколько тонких, но точных жанрово-стилевых элементов рождают образ церковного ритуала, который, в свою очередь, влечет за собой многие художественные и жизненные представления, переживания и мысли.

Третья пьеса содержит ясно выраженную стилизацию военной музыки: короткие фанфарные реплики («трубные гласы») сочетаются с ритмической формулой барабанного боя, агрессивной атакующей артикуляцией, остинатным слоем фактуры. Яркой жанровой образностью отличается и пятая пьеса, полностью построенная на основе ритмофактурной формулы вальса. Заметим также прозрачную аллюзию к фортепианным вальсам Ф. Шопена. Образный строй шестой пьесы цикла почти целиком и полностью детерминирован характером мелодических линий, выдержанных в жанровом стиле драматически напряженного оперного речитатива.

Многоплановостью отличается жанровая образность седьмой пьесы. В ней органично сплавились жанровый стиль протяжной крестьянской венгерской песни, признаки общехудожественного жанра диалогасоревнования и принцип моторной остинатности. Восьмая пьеса цикла стилизует метроритмическую формулу хороводного фольклорного танца с его простым и ярким образным содержанием. Части 4 и 10 не имеют самоочевидных признаков воспроизведенных жанровых стилей. Для их обнаружения требуется пристальный анализ формы. Прекрасно скомпонованный цикл Лигети завершается пьесой, которая по своей образности и стилевым признакам больше, чем другие части цикла, соответствует титульному жанру - ричеркару. Финальная пьеса посвящена 
великому итальянскому мастеру органной импровизации и композиции, одному из родоначальников жанра фуги, автору самых знаменитых ричеркаров Джироламо Фрескобальди. Интонационный характер темы, имитационно-полифоническая фактура, синтаксическое устройство речевого процесса, построение композиции - все эти признаки (за исключением норм неклассического музыкального языка) служат актуализации жанровой образности старинного полифонического жанра ричеркара.

Мы могли бы привести еще огромное множество примеров из произведений композиторов XX века, иллюстрирующих феномен жанровой образности, детерминированной композиторским приемом воспроизведения свойств жанрового стиля в оригинальном музыкальном тексте, то есть приемом жанровой стилизации.

\section{Выводы:}

1. Жанровая образность определена в статье как чувственные представления (картины действительности), эмоции, психические модальности, абстрактные идеи, одним словом - cмысль, которые возникают в художественном восприятии (мышлении, сознании) слушателя и исполнителя музыки вследствие воздействия музыкальновыразительных средств, детерминированных жанром данного музыкального артефракта.

2. Определение жанровых свойств музыкального произведения, в частности - его жанровой образности, предполагает различение: 1) титульного жсанра (обозначенного в нотном тексте или иным способом); 2) фактического жсанра музыкального артефакта; 3) стилизованного жсанра, представленного неким комплексом выразительных средств (конкретно-фоническими, интонационно-речевыми и композиционными свойствами формы).

3. Для современной музыки, в условиях принципиального обновления музыкального языка, музыкально-речевых стилей и принципов музыкальной поэтики, особо важную роль приобретает выразительный прием стилизации жсанра. Он вносит в семантическую структуру произведения жанровую образность, которая обеспечивает определенные культурные коннотации музыкального текста произведения, его связь с традицией, социальной жизнью, сферами литературы, идеологии, религии, обычаев, быта людей.

4. Освоение жанровой образности произведений современной музыки в процессе профессионального обучения музыкантов-исполнителей целесообразно направить на формирование психологической установки восприятия жанровых стилизаций, на выработку умения анализировать 
произведение с точки зрения жанровых стилей, на интенцию понимания и воплощения в звучании специфической жанровой образности.

Овладение мощным художественно-выразительным потенциалом жанровой образности современной фортепианной музыки составляет не только важную, но и трудную художественно-исполнительскую и музыкально-педагогическую задачу. Ее решение требует разработки специальных подходов, методов, приемов, педагогических условий подготовки музыкантов-исполнителей.

1. Алексеев А. Д. История фортепианного искусства : учебник : в 3 ч. Ч. 1-2. 2-е изд., доп. Москва : Музыка, 1988. 415 c.

2. Біла К. Жанрово-стильова модель як універсальна аналітична система // Студії мистецтвознавчі. 2008. Число 2. С. 107.

3. Гаккель Л. Фортепианная музыка ХХ века : Очерки. Ленинград ; Москва : Советский композитор, 1976. 296 с.

4. ИоффеИ.И. Синтетическая история искусств: Введение в историю художественного мышления. Ленинград : ОГИЗ, 1933. 570 с.

5. Клин В. О музыке. Теория жанра и жанры фортепианной литературы. Киев : Музична Україна, 1985. 351 с

6. Леонтьев А. Н. Некоторые проблемь психологии искусства // Избранные психологические произведения : в 2 m. Т. ІІ. Москва : Педагогика, 1983. С. 232-239.

7. Лобанова М. Дьёрдь Лигети - эстетические взгляды и творческая практика 60-70-х годов (Критика и размышления) // Теория и практика современной буржуазной культуры: проблемы критики: сборник трудов. Москва: ГМПИ им. Гнесиных, 1987. Bun. 94. C. 140-172.

8. Михайлов М. Стиль в музыке : Исследование. Ленинград : Музыка, 1981. 262 c.

9. Назайкинский Е. В. Стиль и жанр в музыке : учебное пособие. Москва : Гуманит. изд. ичентр ВЛАДОС, 2003. 248 с.

10. Ольховиков Д. Б. «Образность» как категория филологического описания текста // Res Linguistica. Москва : Academia, 1999. C. 338-357.

11. Платонов К. К. Краткий словарь системы психологчческих понятий. Изд. второе, перераб. и доп. Москва : Высшая школа, 1984. 174 с.

12. Популярная художественная энщиклопедия/под ред. В. М. Полевого. Москва: Издательство «Советская энииклопедия》, $1986 . \quad$ URL: https://dic.academic.ru/dic.nsf/enc_pictures/3093 (дата обращения: 10.05.2018).

13. Роднянская И. Б. Образ // Литературная энииклопедия терминов и понятий/под ред. А. Н. Николюкина. Москва : НПК Интелвак, 2001. С. 669-674.

14. Словарь лингвистических терминов / ред. и сост. Т. В. Жеребило. Изд. 5-е, испр. и доп. Назрань : Пилигрим, 2010. 485 c.

15. Сохор А. Эстетическая природа жанра в музыке // A. Сохор. Вопросы сочиологии и эстетики музыки. Статьи и исследования/ ред.-сост. М. Арановский. Т. 2. Ленинград : Сов. композитор, 1981. С. 231-293.

16. Философский энииклопедический словарь / гл. ред. : Ф. Ильичев, П. Н. Федосеев, С. М. Ковалев, В. Г. Панов. Москва : Сов. энииклопедия, 1983. 840 с. 
17. Шип С. Жанр музичний // Українська музична енџиклопедія. T. 2 [E-К] / редкол. Г. Скрипник (голова) та ін. ; НАН Украӥни ; ІМФЕ ім. М. Т. Рильського. Київ : Вид. Інституту мистеитвознавства, фольклористики та етнологї НАН України, 2008. С. 69-72.

18. Шип С. Стилизаџия как художественно-выразительный прием в современной украинской музыке// Проблемы музыкальной культуры. Bып. 2. Киев: Музична Україна, 1989. С. 86-104.

19. Burge D. Twentieth-Century Piano Music. New York: Schirmer Books, 1990. 284 p.

20. Lan Ping-Ting. New Resources in Twentieth-Century Piano Music and Richard Wilson's Eclogue: Doctor of Musical Arts dissertation (Performance). Denton : University of North Texas, 1974. 89 p.

21. Shockley A. The Contemporary Piano: A Performer and Composer's Guide to Techniques and Resources. Lanham : Rowman \& Littlefield Publishers, 2018. 268 p.

22. Kirby F. E. A Short History of Keyboard Music. New York: Free Press, 1966, 534 p.

23. Gartner K. R. The Expansion of Pianism since 1945 : Ph.D. Thesis. New York: New York University, 1979. 388 p.

\section{References}

1. Alekseev, A. (1988). History of piano art. Vol. 2. Moscow: Muzyka [in Russian].

2. Bila, K. (2008). Genre-style model as a universal analytical system. Studiyi mystetstvoznavchi, 2, p. 107 [in Ukrainian].

3. Gakkel, L. (1976). Piano music of the twentieth century. Leningrad;-Moscow: Sovietskii kompozitor [in Russian].

4. Ioffe, I. (1933). Synthetic art history: An introduction to the history of artistic thinking. Leningrad: OGIZ [in Russian].

5. Klin, V. (1985). About music. The genre theory and genres of piano literature. Kiev: Muzichna Ukrayina [in Russian].

6. Leontiev, A. (1983). Some problems of the psychology of art. Izbrannyie psihologicheskie proizvedeniya. Vol. II. Moscow: Pedagogika [in Russian].

7. Lobanova, M. (1987). György Ligeti - aesthetic views and creative practice of 60-70s (Criticism and Reflections). Teoriya i praktika sovremennoy burzhuaznoy kultury: problemy kritiki, 94, pp. 140-172 [in Russian].

8. Mihailov, M. (1981). Style in music. Leningrad: Muzyka [in Russian].

9. Nazaykinskiy, E. (2003). Style and genre in music. Moscow: VLADOS [in Russian].

10. Olhovikov, D. (1999). "Image" as a category of a philological description of the text. Res Linguistica. Moscow: Academia, pp. 338-357 [in Russian].

11. Platonov, K. (1984). Concise Dictionary of the system of psychological concepts. Moscow: Vysshaya shkola [in Russian].

12. Polevoi, V. (Ed.). (1986). Popular Art Encyclopedia. Moscow: Sovetskaya entsiklopediya. [online] Available at: https://dic.academic.ru/dic.nsflenc_pictures/3093 [Accessed 10 May 2018] [in Russian].

13. Rodnyanskaya, I. (2001). Image. Literaturnaya entsiklopediya terminov i ponyatiy. A. Nikolyukin (Ed.). Moscow: NPK Intelvak, pp. 669-674 [in Russian].

14. Zherebilo, T. (Ed.). (2010). Dictionary of linguistic terms. Nazran: Piligrim [in Russian]. 
15. Sohor, A. (1981). The aesthetic nature of the genre in music. Voprosy sotsiologii i estetiki muzyki. Statti $i$ issledovaniya. M. Aranovskiy (Ed.). Vol. 2. Leningrad: Sovetskiy kompozitor, pp. 231-293 [in Russian].

16. Ilichev, F. (Eds.). (1983). Philosophical Encyclopedic Dictionary. Moscow: Sovetskaya Entsiklopediya [in Russian].

17. Ship, S. (2008). Genre musical. Ukrayinska muzichna entsiklopediya. Vol. 2. G. Skripnik (Eds.). Kyiv: Vydavnytstvo Instytutu mystetstvoznavstva, folklorystyky ta etnologiyi NAN Ukrayiny, pp. 69-72 [in Ukrainian].

18. Ship, S. (1989). Stylization as an artistic and expressive technique in contemporary Ukrainian music. Problemy muzyikalnoy kultury, 2, pp. 86-104 [in Russian].

19. Burge, D. (1990). Twentieth-Century Piano Music. New York: Schirmer Books [in English].

20. Lan, Ping-Ting (1974). New Resources in Twentieth-Century Piano Music and Richard Wilson's Eclogue. D.M.A. thesis (Performance). Denton: University of North Texas [in English].

21. Schokley, A. (2018). The Contemporary Piano. A Performer and Composer's Guide to Techniques and Resources. Lanham: Rowman \& Littlefield Publishers [in English].

22. Kirby, F. (1966). A Short History of Keyboard Music. New York: Free Press [in English].

23. Gartner, K. (1979). The Expansion of Pianism since 1945. Ph.D. thesis. New York: New York University [in English]. 